Revista Cógnito 01 (2019) 131-144

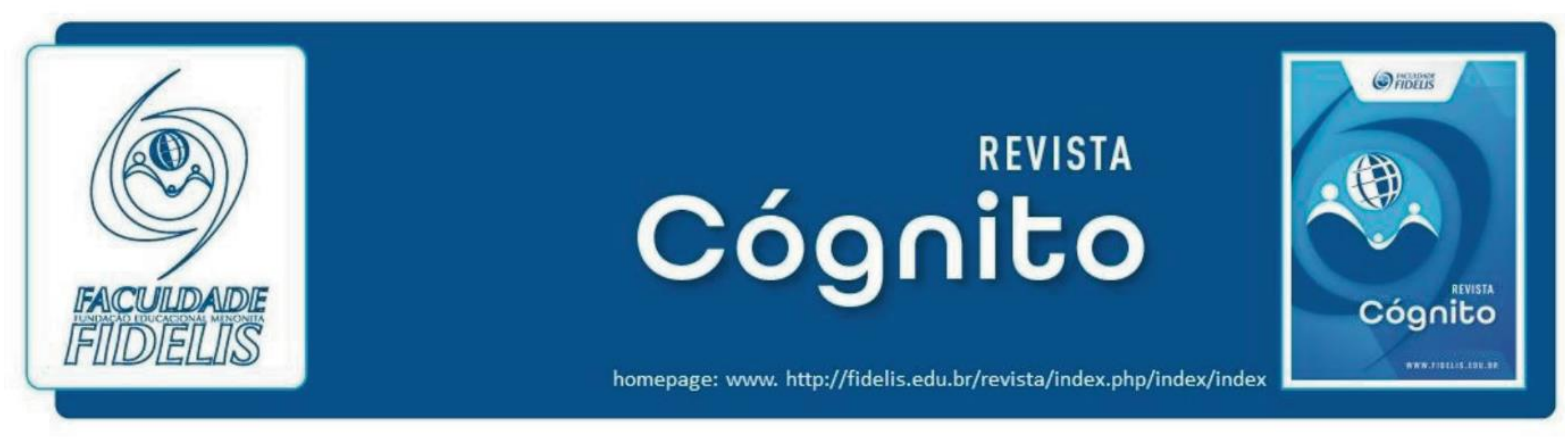

\title{
UMA NOVA PRÁXIS PARA A RECONSTRUÇÃO DA AVALIAÇÃO NO PROCESSO DE ENSINO-APRENDIZAGEM
}

\author{
Bruna Cristine Pizzaia ${ }^{1}$ \\ Milena Silveira dos Santos ${ }^{2}$ \\ Angela Maria Gomes ${ }^{3}$
}

\begin{abstract}
RESUMO
O presente artigo apresenta os conceitos e definições da avaliação no processo de ensinoaprendizagem do educando. Abordamos o processo avaliativo e suas modalidades: formativa e somativa, onde os instrumentos de avaliação são confrontados, uma visa a construção do conhecimento do aluno durante todo o seu percurso escolar, a outra intenta somente avaliação por meio de provas e outras atividades tradicionais, cuja a finalidade é a obtenção de nota para aprovação no ano escolar. Refletimos também a importância da reconstrução do processo avaliativo com uma nova práxis para realinhar métodos que estão prejudicando os alunos, os únicos que necessitam aprender para ter um futuro pessoal e profissional melhor. Sabemos que atualmente os métodos avaliativos são um pouco engessados, não estimulando o aluno ao processo de ensino e aprendizagem de forma autônoma. Neste sentido, o professor tem o papel de mediador, e o educando o protagonista de sua aprendizagem. Trazemos a nova prática para o processo de avaliação voltado como um método, um guia do processo de ensino aprendizagem, e não apenas uma verificação de acertos e erros. Para isto apostamos na avaliação híbrida. Nossos alunos mudaram, é fato, e nossa forma de avaliar também necessita de mudanças.
\end{abstract}

Palavras chave: Avaliação; Ensino-aprendizagem; Professor; Aluno

\footnotetext{
${ }^{1}$ Especialista em Gestão das Organizações de Ensino - UP. Coordenadora da Faculdade Fidelis. bruna.pizzaia@erasto.com.br

${ }^{2}$ Especialista em Formação Docente para o EAD - Uninter

${ }^{3}$ Especialista em Gestão do Treinamento e Desenvolvimento - PUC/PR. Docente da faculdade Fidelis. angela.gomes@fidelis.edu.br
} 


\section{INTRODUÇÃO}

Atualmente uma das atividades docentes que mais tem repercutido na vida dos nossos educandos, tem sido o processo avaliativo. Não é surpresa que muitos professores ainda utilizem a prova escrita como único instrumento para verificação do rendimento escolar. Diversificar os instrumentos de avaliação requer planejamento e organização do professor. Precisamos ter objetivos claros para que o momento avaliativo alcance o alvo de ajudar o aluno em sua construção do conhecimento.

Precisa-se entender a real importância da avaliação dentro do processo de ensino e aprendizagem. A avaliação necessita dar significado aos conteúdos apresentados, aproximando a prática da teoria, não excluindo a correlação com a sociedade.

Vivemos ainda em um sistema de ensino brasileiro, o qual atribui a aprendizagem ao alcance de notas numéricas para avanço nos estudos. A situação de avaliar por meio de notas, limita-se a apontar somente erros dos alunos, e não é este o objetivo, a real importância da avaliação é acompanhar e desenvolver o aluno por completo. Para isso, este artigo aponta a necessidade de reconstrução do processo avaliativo por meio dos recursos da metodologia ativa voltada para o ensino híbrido, o qual o foco está concentrado não no erro, mas sim na oportunidade de melhoria.

Neste contexto, este artigo teve como questão problematizadora: Como a avaliação escolar pode ajudar na reconstrução da aprendizagem?

Para responder à problemática foram elencados os seguintes objetivos: descrever os conceitos e definições da avaliação, identificar os processos avaliativos e suas modalidades: formativa e somativa e apontar a importância da reconstrução do processo avaliativo com uma nova práxis.

Este artigo tem como metodologia a pesquisa bibliográfica, desta forma, foram feitas pesquisas em livros e artigos científicos sobre a temática para uma melhor compreensão do objeto de estudo. Optou-se pelo estudo bibliográfico buscando o aprofundamento necessário para compreensão de tal tema, discutindo e apontando os estudos dos principais autores da área, como Both (2012, 2017), Luckesi (2002) e Arredondo e Diago (2013). 
Segundo Ruiz (2002, p. 58): “A pesquisa bibliográfica consiste no exame desse manancial, para levantamento e análise do que já se produziu sobre determinado assunto que assumimos como tema de pesquisa científica”.

\section{UMA NOVA PRÁxis PARA A RECONSTRUÇÃo DA AVALIAÇÃo NO PROCESSO DE ENSINO APRENDIZAGEM}

\subsection{CONCEITOS E DEFINIÇÕES DA AVALIAÇÃO}

A avaliação é entendida como uma prática pedagógica, naturalmente estabelece um conjunto com a aprendizagem e o desempenho, onde se completam pedagogicamente. A avaliação precisa ser cuidada tanto no planejamento, quanto na execução, ela também é definida como um meio para perceber e identificar como está o desempenho dos alunos, e não para apenas apontar os erros e acertos.

Assim esclarece Both (2012, p. 40):

Percebemos que avaliar também significa apoiar intensamente o ser humano em suas dificuldades de aprendizagem. A ação de avaliar jamais sugere punição, tampouco humilhação ante eventuais dificuldades de aprendizagem e de desempenho pessoal e profissional.

Assim, dialogando com as palavras de Both, professores ao finalizar suas avaliações não devem punir, ou até mesmo castigar, seus alunos por insucesso ou erros no processo de aprendizagem, pois podem causar traumas para sua vida educacional.

Luckesi (2002, p. 58) afirma:

De fato, a avaliação da aprendizagem deveria servir de suporte para a qualificação daquilo que acontece com o educando, diante dos objetivos que se têm. [...] A avaliação não deveria ser fonte de decisão sobre o castigo, mas de decisão sobre os caminhos do crescimento sadio e feliz.

Após todo e qualquer processo avaliativo é necessário realizar o feedback com o aluno, com a finalidade de apontar as oportunidades de melhoria em seu processo de ensino e 
aprendizagem. Aqui, há de se destacar que o próprio docente deve se auto avaliar, deixando de lado seus conceitos já formados.

Para Boufleuer

\begin{abstract}
Nessa nova perspectiva, a avaliação se insere na dinâmica de uma aprendizagem entendida como construção do conhecimento, o que exige uma mudança de atitude tanto do professor como do aluno. O professor precisa superar a expectativa de ter na resposta do aluno o reflexo de sua própria aprendizagem. $\mathrm{O}$ aluno, por sua vez, deve sentirse suficientemente encorajado para manifestar a sua aprendizagem da forma como conseguiu significá-la no contexto de suas referências e experiências (2003, p.29).
\end{abstract}

O ato de avaliar é muito amplo dentro do meio educacional e não se restringe a um único objetivo, avaliar não consiste somente o foco no aluno e sim, em todo seu processo de aprendizagem.

Assim complementa Sant' Anna (1998, p. 29,30) dizendo que a avaliação é:

Um processo pelo qual se procura identificar, aferir, investigar e analisar as modificações do comportamento e rendimento do aluno, do educador, do sistema, confirmando se a construção do conhecimento de processou, seja este teórico (mental) ou prático.

Contextualizando com as palavras de Sant' Anna, Demo (1999, p. 01) afirma a importância do processo da avaliação sobre refletir e planejar os objetivos e propósitos no ato avaliativo:

Refletir é também avaliar, e avaliar é também planejar, estabelecer objetivos etc. Daí os critérios de avaliação, que condicionam seus resultados estejam sempre subordinados a finalidades e objetivos previamente estabelecidos para qualquer prática, seja ela educativa, social, política ou outra.

$\mathrm{O}$ ato de avaliar inicia quando o professor elabora seu planejamento, ele deve ter uma avaliação prévia do conhecimento de cada aluno, para a partir disso elaborar e apresentar um novo conteúdo. Segundo Weisz e Sanchez (2009, p. 93): “conhecer essas ideias e representações prévias ajuda muito na hora de construir uma situação na qual o aluno terá de usar o que já sabe para aprender o que ainda não sabe".

Entende-se que a avaliação prévia dos alunos subsidia decisões e escolhas para os instrumentos do ensino, descobrindo o nível de conhecimento de cada um, assim favorecendo 
os objetivos da aprendizagem. Both (2012, p. 168) explica: "avaliar, na verdade, é perceber a quantas anda a aprendizagem dos alunos, e não somente descobrir o quanto e em que nível os alunos dominam conteúdos ou o quanto e em que nível eles ou têm em falta”.

Dentro desse processo de avaliação, trabalha-se junto a mediação, por meio desta aproximação elabora o histórico dos conhecimentos prévios dos alunos. Entendem-se os momentos de aprendizagem de cada indivíduo e seu modo de aprender, Hoffmann (2001, p. 51) afirma:

\begin{abstract}
Mediação é aproximação, diálogo, acompanhamento do jeito de ser e aprender de cada educando, dando-lhe a mão, com rigor e afeto, para ajudá-lo sempre, tendo ele a opção de escolha de rumos em sua trajetória de conhecimento. O tempo do aluno que precisa ser, sobretudo, respeitado é o tempo de aprender e o tempo de ser e não o tempo "de aprender determinado conteúdo".
\end{abstract}

Refletindo sobre os apontamentos de Hoffmann, existe tempo para cada processo, por isso a avaliação é primordial no início do planejamento de ensino. Por meio desta avaliação inicial, o professor identifica quais dificuldades seu aluno apresenta e em qual aspecto dentro da aprendizagem ele tem mais afinidade. Podemos destacar aqui a avaliação diagnóstica como aliada ao processo de aprendizagem.

Both (2012, p. 168), também explica abordando sobre os instrumentos de avaliação que auxiliam no processo: “outro aspecto não menos importante academicamente é o avaliador perceber mediante qual tipo de instrumento de avaliação cada aprendiz consegue demonstrar melhor o seu domínio de conhecimento". Assim não correra o risco de aplicar um método de ensino que prejudique ou dificulte a aprendizagem do aluno, que em alguns casos somente na avaliação é percebido.

Refletindo sobre o conceito de Both, para que os instrumentos avaliativos sejam bem elaborados e percebidos pelo avaliador, o mesmo deve ter pleno domínio do que esta fazendo, sua formação deve ser voltada e alinhada para a avaliação educacional, para que não ocorram erros em seu processo.

Assim confirma Vianna (1989, p. 24):

A avaliação educacional exige a participação de profissionais especialmente treinados, com experiência no trato de diferentes problemas educacionais, e possuidores de capacitação específica para o exercício da função. 
Mas a experiência e o domínio do educador não devem ser somente refletidos sobre sua formação técnica, ele precisa também trazer de si o dom e o gostar pela profissão, para assim poder ensinar seus alunos. Para Luckesi (2002, p. 172), a avaliação da aprendizagem é compreendida como um ato de amor: "defino a avaliação da aprendizagem como um ato amoroso, no sentido de que a avaliação, por si, é um ato acolhedor, integrativo, inclusivo".

Enfim, não existe um conceito ou definição concreto para a avaliação, dentro deste processo existem diversos itens a serem apontados que visam somente um objetivo, a aprendizagem do aluno. Dialogando com o autor Both (2012, p. 106), ele relata que é possível desenvolver outro conceito para a avaliação juntamente com a aprendizagem: "avaliação é um processo de valorização da aprendizagem e do desempenho intelectual, educacional e social do indivíduo".

\title{
2.1 PROCESSO AVALIATIVO E SUAS MODALIDADES: FORMATIVA E
} SOMATIVA

Dentro do processo avaliativo existem modelos e funções que são utilizados para avaliar a aprendizagem do aluno, mas que muitas vezes existe a dificuldade de ter clareza entre as modalidades e também na aplicação na prática. Assim este artigo apontará duas dessas funções e explicará como elas são desenvolvidas nos processos dentro da escola e qual sua real importância.

Complementando Both (2012, p. 30) explica:

\begin{abstract}
As avaliações formativa e somativa compõem a coluna central da qual derivam todas as demais inciativas consequentes da ação de avaliar. Falar em formativa (processual) e somativa não constitui novidade para ninguém. No entanto, o que muitas vezes causa mais dificuldades é a falta de uma clara concepção e aplicação pratica dessa avaliação tanto nos meios educacionais quanto nos sociais.
\end{abstract}

\subsubsection{Avaliação Formativa}

A avaliação formativa tem por finalidade constatar se o aluno esta absorvendo o conteúdo com ou sem dificuldade, assim localizando a deficiência no planejamento do ensino- 
aprendizagem. Ela não requer nota, mas sim o acompanhamento do desempenho do aluno durante o seu percurso escolar, assim confirma Both (2012, p. 31):

Percebemos que a avaliação processual (formativa) encontra-se sempre próxima do aluno em sua fase escolar, acompanhando-o passo a passo e dia a dia em seu esforço de estudante - mantendo o empenho pela melhoria do desempenho do aluno.

Entendemos então que este modelo de avaliação percorre todo o período da fase escolar dos alunos para apontar melhorias no processo de ensino-aprendizagem. Sant'Anna também explica que a avaliação formativa tem o sentido de indicar se os alunos estão se modificando, para assim, alcançarem os seus objetivos:

Formativa tem como função informar o aluno e o professor sobre os resultados que estão sendo alcançados durante o desenvolvimento das atividades; melhorar o ensino e a aprendizagem; localizar, apontar, discriminar deficiências, insuficiências, no desenvolvimento do ensino-aprendizagem para elimina-las; proporcionar feedback de ação (leitura, explicações, exercícios). (SANT’ANNA, 2001, p. 34)

Desse modo a avaliação formativa vem para ajudar o professor em sala de aula, pois, por meio desta avaliação, o mesmo identificará se seu planejamento está de acordo ou se precisa ser alterado após os relatos das dificuldades dos alunos. Kraemer (2005, p. 8) confirma dizendo que "estes mecanismos permitem que o professor detecte e identifique deficiências na forma de ensinar, possibilitando reformulações no seu trabalho didático, visando aperfeiçoa-lo".

Os autores Arredondo e Diago remetem a avaliação formativa como um processo de mudança, de adaptação, para que seja desenvolvido conforme as necessidades e características de cada aluno:

A avaliação formativa, no âmbito psicopedagógico, permite adaptar as atividades de ensino e aprendizagem as características pessoais dos alunos, com a finalidade de ajustar as tarefas propostas ao que eles são capazes de fazer. (Arredonto; Diago, 2012, p. 55)

Pode se entender que a avaliação formativa talvez seja uma das mais importantes no meio educacional, pois é uma avaliação que acontece com frequência e visa o desempenho do aluno, tornando o processo mais eficaz, sem a pressão de alcançar uma nota para uma futura aprovação.

Para que esse ato de avaliar não seja visto negativamente pelos professores, como um trabalho extra ou até mesmo cansativo, precisam-se criar alguns métodos para que a avaliação 
ocorra diariamente. Morales (2003, p. 46) cita alguns exemplos: “[...] métodos simples de avaliação dividindo-o em três seções: perguntas orais, perguntas abertas e perguntas objetivas". Ele explica também que: [...] "cada professor pode complementar de acordo com sua disciplina, sua experiência e sua experimentação".

Corroborando com Morales, entende-se novamente que a avaliação formativa é flexível, pois além do professor conseguir decifrar as dificuldades dos alunos, ele também pode utilizar de outros métodos para que o processo seja efetivado com sucesso.

\subsubsection{Avaliação Somativa}

A avaliação somativa é identificada como aquela que menciona nota para cada avaliação realizada e que no final acarretará a aprovação, ou não, do mesmo. Hoje a maioria das escolas trabalha com este método, pois é o único que classificará por meio de notas se o aluno está apto ou não para promoção. Segundo Both (2012, p. 31): “o aspecto somativo, por sua vez, representa o desempenho dos estudantes de forma pontual, no qual os resultados são demonstrados numericamente".

Esse processo avaliativo é desenvolvido como a avaliação formativa deste o início do processo de ensino-aprendizagem, mas tem por finalidade indicar se os resultados obtidos serão necessários para aprovação ou reprovação do aluno. Assim ratificam Arredonto e Diago (2013, p. 55) "a avaliação somativa é final (de um período ou do curso), e suas decisões têm explicações administrativas, de promoção, certificação ou graduação".

Para a autora Haydt, a avaliação somativa tem a função de classificar os alunos ao final do processo de ensino, sendo este o objetivo de classificar no seu processo quantitativo e assim vinculando-o com a ação de medir:

\footnotetext{
Medir significa determinar a quantidade, a extensão ou o grau de alguma coisa, tendo por base um sistema de unidades convencionais. Na nossa vida diária estamos constantemente usando unidades de medidas, unidades de tempo. O resultado de uma medida é expresso e números. Daí a sua objetividade e exatidão. A medida se refere sempre ao aspecto quantitativo do fenômeno a ser descrito. (HAYDT 2000, p. 9)
}

A avaliação somativa nem sempre se realiza no final do processo de ensinoaprendizagem, ela pode ser desenvolvida junto com a avaliação formativa, com métodos que diferencie as avaliações padrões e obrigatórias, tais como, provas, trabalhos e apresentações. Assim confirma Both (2012, p. 31 e 32): "não podemos dizer que a avaliação somativa esteja 
de todo modo distante do aluno durante seu período escolar, ainda que pedagogicamente esta não se faça tão efetiva quanto a primeira".

Assim, entende-se que esta avaliação percorre todo o caminho próximo ao aluno, mas que não tão próxima como a avaliação formativa. O professor precisa ter o discernimento de diferencia-las e entender que cada uma se manifesta de forma diferente, pois enquanto uma avalia o processo, a outra apresenta valores numéricos. Both as relaciona como avaliação (formativa) e verificação (somativa), ele explica que com esta relação elas podem sim trabalhar em conjunto, pois "sua interação operacional é bem possível, uma vez que valores quantitativos ajudam a explicar fatores qualitativos". (BOTH, 2017, p. 43)

No quadro 1, apontamos em análise a comparação entre avaliação (formativa) e verificação (somativa):

Quadro 1 - Comparativo entre avaliação e verificação

\begin{tabular}{|l|l|}
\hline Avaliação & Verificação \\
\hline Dinâmica & Estática \\
\hline Qualitativa & Quantitativa \\
\hline Diagnóstica & Constatação \\
\hline Democrática & Autoritária \\
\hline Construtiva & Verificativa \\
\hline Subjetiva & Metafísica \\
\hline Autônoma & Submissa \\
\hline
\end{tabular}

Fonte: Adaptado de BOTH, 2017, p. 43.

O quadro 1 compara as diferenças entre as duas avaliações, demonstrando que nenhuma consegue concretizar sozinha o processo avaliativo do aluno. Cada uma apresenta um objetivo que precisa ser alcançado, a formativa deve acompanhar o desenvolvimento do aluno durante todo o processo avaliativo e a somativa ao findar da etapa educacional. Villas Boas afirma que:

A diferença fundamental entre a avaliação somativa e formativa não é o momento da sua realização, mas os propósitos de cada uma. Com frequência, ouve-se alguém dizer que a avaliação somativa desenvolve-se ao final do processo e a formativa, durante o processo. Acontece que as duas podem realizar-se em um ou em outro momento. Os seus objetivos é que são diferentes. (VILLAS BOAS, 2015, p. 32) 
Finalizando esta temática, entende-se que processos avaliativos são de extrema importância, indiferente de seus objetivos ou se qual é melhor devem ser trabalhados em conjunto para assim desenvolver um único indivíduo, o aluno. Este que esta presente em sala para aprender aquilo que não conhece, que ele nunca viu, mas que confia em seu professor que lhe transbordará de conhecimentos e ao final avaliará seu desenvolvimento indiferente de modelos de avaliação.

\subsection{A IMPORTÂNCIA DA RECONSTRUÇÃO DO PROCESSO AVALIATIVO COM UMA NOVA PRÁXIS}

Compreendemos que a avaliação é uma prática pedagógica, desenvolvida juntamente com o planejamento, para contribuir no processo de ensino-aprendizagem do aluno. É por meio dela que a escola obtém os resultados educacionais, observando questões como rendimento, frequência, metodologias utilizadas e satisfação da comunidade. Assim, a avaliação é um processo que precisa ser construído coletivamente.

Devemos entender que a avaliação não deve ter o sentido de repreensão e humilhação com os resultados negativos dos alunos, Both (2012, p. 40) explica: "a ação de avaliar jamais sugere punição, tampouco humilhação ante eventuais dificuldades de aprendizagem e de desempenho pessoal e profissional".

É natural que um indivíduo tenha dificuldades em seu processo de aprendizagem, mas existem aqueles com um grau maior, que muitas vezes nem em casa conseguem solucionar. $\mathrm{O}$ professor precisa entender as dificuldades dos alunos e propor um novo método de ensino, e assim orientar e direciona-los, pois esta é sua função frente à sala de aula, Vasconcellos afirma:

\footnotetext{
A atenção do professor deve ser proporcional às necessidades de cada aluno, portanto, dedicando-se mais aos alunos com maiores dificuldades, sensibilizando, inclusive, os demais alunos nesta mesma direção. (VASCONCELLOS, 2008, p. 55)
}

Percebe-se que a avaliação é um ato de extrema importância no meio escolar, sem este processo não é possível identificar se o aluno esta aprendendo ou até mesmo se a metodologia do professor esta adequada. Para isso é preciso que o professor revise seu planejamento e interprete seu método avaliativo, como explica Chueiri: 
Na condição de avaliador desse processo, o professor interpreta e atribui sentidos e significados à avaliação escolar, produzindo conhecimentos e representações a respeito da avaliação e acerca de seu papel como avaliador, com base em suas próprias concepções, vivências e conhecimentos. (Chueiri, 2008, p. 52)

$\mathrm{Na}$ atual realidade escolar, a avaliação é somente representada pelo método quantitativo, referenciando-se a notas para a aprovação do aluno, que caso não as obtenha é reprovado. É necessário aplicarmos uma nova práxis, reconstruindo o método avaliativo juntamente com o processo de ensino-aprendizagem.

Apoiados nos diversos recursos pautados nas Metodologias Ativas, as quais têm a essência onde o aluno assumi o papel de protagonista de sua aprendizagem, e o professor atua como mediador, mentor que instiga o aluno a pensar de forma crítica e significativa, tendo autonomia no processo de aprendizagem planejado antecipadamente pelo professor.

Para Moran, "se queremos que os alunos sejam proativos, precisamos adotar metodologias em que os alunos se envolvam em atividades cada vez mais complexas [...]”, (MORÁN, 2015, p. 17).

A avaliação da aprendizagem atualmente precisa de novos paradigmas. Faz-se necessária a readequação conforte o perfil dos alunos e da nova sociedade. Deve-se contemplar o processo qualitativo, que visa o desenvolvimento escolar e profissional do aluno durante todo o seu percurso de aprendizagem. Neste sentido Kraemer afirma:

\footnotetext{
Se as nossas metas são educação e transformação, não nos resta outra alternativa senão juntos pensar uma nova forma de avaliação. Romper paradigmas, mudar nossa concepção, mudar a prática, é construir uma nova escola. (KRAEMER, 2005, p. 15)
}

Mas para que esta mudança aconteça, precisa entender que a avaliação é um ato amoroso, que acolhe atos, ações, alegrias e dores, para assim construir um novo modelo que atenda todas as necessidades dos alunos, desta forma Luckesi confirma:

Defino a avaliação da aprendizagem como um ato amoroso, no sentido de que a avaliação, por si, é um ato acolhedor, integrativo, inclusivo. [...] A avaliação tem por base acolher uma situação, para, então (e só então), ajuizar a sua qualidade, tendo em vista dar-lhe suporte de mudança, se necessário. (Luckesi, 2002, p. 172)

Apontamos como uma nova práxis a aprendizagem baseada em problema PBL(Problem Based Learning ), a qual o aluno é avaliado continuamente, segundo os objetivos propostos de forma clara e antecipada. Entendemos a PBL como uma quebra de paradigma nos 
métodos de ensino tradicional. Ao submetermos os alunos a esta prática, haverá interações em grupo e individual, as quais despertaram o educando ao aprender de forma mais profunda.

Finalizamos este artigo, porém não a reflexão, com o intuito de instigar essa mudança nos métodos de avaliação, visando à melhoria do processo de ensino-aprendizagem. Pois, conforme ponderado, ambos os lados do processo são prejudicados nesta ação. O aluno, que está ali neste espaço escolar para aprender, conhecer coisas que somente muitas vezes verá somente na escola e o próprio educador que perde uma significante oportunidade de auto avaliação.

Sabemos que precisamos de muito para mudar este grande processo, mas aos poucos os instrumentos e métodos vão se realinhando e a sociedade concretizando que o melhor meio avaliativo é aquele que visa o crescimento do aluno e não somente a nota para a sua aprovação e progressão escolar.

\section{CONCLUSÃO}

Esta pesquisa teve a intenção de provocar uma reflexão sobre o processo avaliativo e a importância da sua reconstrução. Os professores e a escola precisam analisar seus métodos e seus planejamentos, para assim transmitir aos seus alunos o conhecimento de uma nova forma representativa. Utilizando-se dos métodos avaliativos, não como apenas uma forma de aferir notas para aprovação ou reprovação, mas como também uma oportunidade de aprendizado e construção do saber.

O conhecimento apresentado no decorrer da pesquisa traz dados relevantes para melhor compreensão do tema e sua importância para o contexto atual da sociedade.

Vivenciamos uma grande evasão nas escolas por alunos que reprovam ou se sentem desmotivados pelo baixo rendimento escolar, referindo-se aqui a notas apenas. Essa realidade carece mudar, precisamos criar novos métodos para aplicar em sala de aula e ajudar estes alunos. Pois, são estes que seguirão em um meio que, muitas vezes, não identifica o processo da educação com objetivos de transformação da sociedade.

A qualificação dos professores precisa ser revista também, eles precisam progredir juntamente com seus alunos, estamos formando indivíduos que precisam aprender a lutar por uma sociedade melhor. 
A avaliação é um processo a ser construído coletivamente, então se deve envolver os pais e a comunidade nesse processo de mudança, realizar reuniões e expor as ideias e propostas para que a avaliação seja qualitativa, que vise a construção do conhecimento do aluno.

Seguindo este intento, a continuidade da pesquisa sobre a avaliação escolar se faz necessária, tendo em vista as transformações contínuas da sociedade. É necessário refletir sobre o tema., como se apresentará no futuro o processo ensino aprendizagem, as perspectivas de melhoria continua e como os envolvidos na educação reagirão com esta reconstrução do processo avaliativo.

Não podemos deixar este assunto findar, pois a sociedade só está a crescer e a educação é o melhor meio para uma transformação significativa, com cidadãos reflexivos, conscientes e com senso crítico desenvolvido. O meio educacional precisa se unir para realizar essa mudança. Pesquisadores e pensadores da Educação podem e devem cada vez mais ir à busca da resolução desta problemática.

\section{REFERÊNCIAS}

ARREDONDO, Santiago Castilho; DIAGO, Jesús Cabrerizo. Avaliação educacional e promoção escolar. Curitiba: InterSaberes, 2013 (e-book).

BOTH, Ivo José. Avaliação: "voz da consciência” da aprendizagem. Curitiba: InterSaberes, 2012.

BOTH, Ivo José. Avaliação planejada, aprendizagem consentida: é ensinando que se avalia, é avaliando que se ensina. Curitiba: InterSaberes, 2017 (e-book).

CHUEIRI, Mary Stela Ferreira. Concepções sobre a Avaliação Escolar. Estudos em Avaliação Educacional, jan./abr. 2008. Disponível em:

https://www.fcc.org.br/pesquisa/publicacoes/eae/arquivos/1418/1418.pdf. Acesso em: 20 jul. 2018.

DEMO, Pedro. Avaliação qualitativa. Campinas: Autores Associados, 1999.

HAYDT, Regina Cazaux. Avaliação do processo ensino-aprendizagem. São Paulo: Ática, 2000.

HOFFMANN, Jussara. Avaliar para promover: as setas do caminho. Porto Alegre: Mediação, 2001.

KRAEMER, Maria Elisabeth Pereira. Avaliação da aprendizagem como construção do saber. V Colóquio Internacional sobre Gestión Universitaria en la América del Sur. Mar del Plata, dez./2015. Disponível em: < http://repositorio.ufsc.br/xmlui/handle/123456789/96974> Acesso em: 01 ago. 2018.

LUCKESI, Cipriano Carlos. Avaliação da aprendizagem escolar. São Paulo: Cortez, 2002. 
MORALES, Pedro. Avaliação escolar: o que é e como se faz. Tradução de Nicolás Nyimi Campanário. São Paulo: Edições Loyola, 2003 (e-book).

RUIZ, João Álvaro. Metodologia científica: Guia para eficiência nos estudos. São Paulo: Atlas, 2002.

SANT'ANNA, Ilza Martins. Por que avaliar?: Como avaliar?: critérios e instrumentos. Vozes: Petrópolis, 2001.

VASCONCELlOS, Celso dos Santos. Avaliação a aprendizagem: Práticas de Mudança por uma práxis transformadora. São Paulo: Libertad, 2008.

VIANNA, Heraldo Marelim. Introdução à avaliação educacional. São Paulo: Ibrasa, 1989.

VILLAS BOAS, Benigna Maria de Freitas. Portfólio, avaliação e trabalho pedagógico. Campinas: Papirus, 2015 (e-book).

WEISZ, Telma; SANCHEZ, Ana. O diálogo entre o ensino e a aprendizagem. São Paulo: Ática, 2009. 